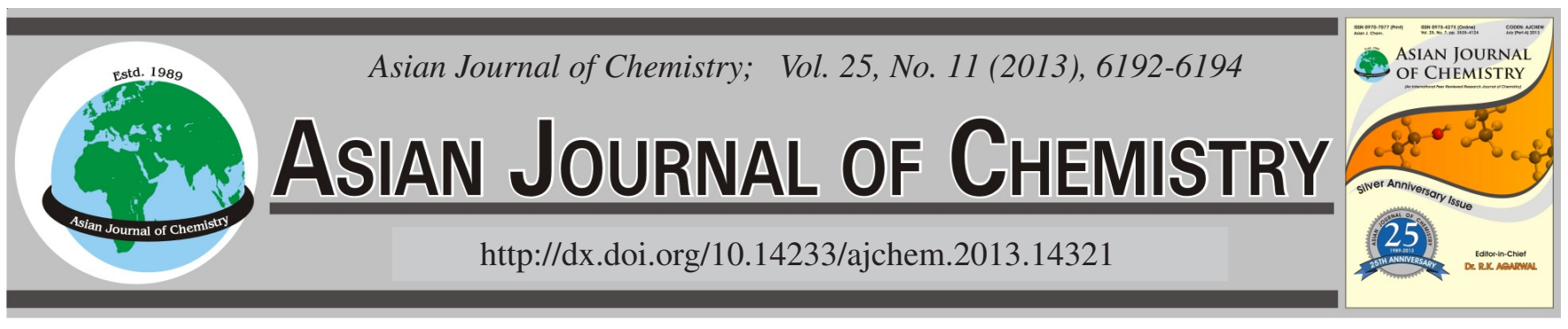

\title{
Phamacognostical Evaluation and Antimicrobial Activity of Paeonia sinjiangensis K.Y. Pan in Xinjiang, China
}

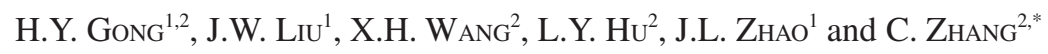

${ }^{1}$ Xinjiang Medical University, Urumqi 830000, Xinjiang Province, R.P. China

${ }^{2}$ The Fifth Affiliated Hospital of Xinjiang Medical University, Urumqi 830000, Xinjiang Province, R.P. China

*Corresponding author: Fax: +86 991 4366927; Tel: +86 15981757393; E-mail: gonghaiyan1217@ sina.com

(Received: 16 July 2012;

Accepted: 2 May 2013)

AJC-13433

This paper deals with the phamacognostical evaluation of the crude drug Paeonia sinjiangensis K.Y. Pan, which is a perennial herb |
belonging to the family Ranunculaceae and an important crude drug in Traditional Chinese Medicine. The microscopic, physico-chemical,
preliminary physicochemical parameters were presented in this work may be to establish the authenticity of Paeonia sinjiangensis K.Y. Pan
and can possibly help to differentiate the drug from its other species. Meanwhile, it was determined total phenols and tested for its
antimicrobial activity in this study. The total phenols content of Paeonia sinjiangensis K.Y. Pan was $9.58 \pm 1.03$ mg QE/g dry wt. It showed
strong inhibition against Blastomyces albicans and possessed considerable activity against Staphylococcus aureus and Escherichia coli.

Key Words: Paeonia sinjiangensis K.Y. Pan, Phamacognostical evaluation, Total phenols, Antimicrobial activity.

ᄂ _ _ - - - - - - - - - - - - - - - - - - - - - - - - - - -

\section{INTRODUCTION}

Paeonia sinjiangensis K.Y. Pan, belonging to Ranunculaceae family $^{1}$, is a perennial herb. It is native of Xinjiang in China and naturalized in the Altai mountain area, especially mostly in the western Xinjiang region. In traditional Chinese medicine, as an important crude drug, it has functions of stabilizing erythrocyte membrane structure ${ }^{2}$, inhibiting aggregation of platelet $^{1}$ and stimulating hepatic cell regeneration ${ }^{3,4}$, removing thrombus, preventing coagulation ${ }^{5}$, avoiding hepatic stopping atherosclerosis, protecting heart and liver and antitumor ${ }^{6}$, etc. It is also frequently used as a remedy for diseases of women ${ }^{7}$.

In recent years, our research group have studied the contents of paeoniflorin by rapid resolution liquid chromatography and polysaccharide with orthogonal test design from $P$. sinjiangensis K.Y. $\mathrm{Pan}^{8}$. The other studies concern on the contents of paeoniflorin from Radix paeoniae rubra ${ }^{9,10}$.

In spite of the numerous medicinal uses attribute to this plant, the pharmacognosy information and antimicrobial activity about $P$. sinjiangensis K.Y. Pan in Xinjiang of China has not yet been published. Hence, the present investigation is an attempt to determine total phenols and its antimicrobial activity.

\section{EXPERIMENTAL}

The plants were collected in October 2010, locally from the Altai mountain area of Xinjiang, China. The voucher specimen was authenticated as $P$. sinjiangensis K.Y. Pan by
Yonghe $\mathrm{Li}$, a chief apothecary of the Traditional Chinese Medicine Hospital of Xinjiang and accessioned into the herbarium of Traditional Chinese Medicine Ethnical Herbs Specimen Museum of Xinjiang Medical University for future reference (the voucher specimen number: 2010-356).

Folin-Ciocalteu phenol reagent, petroleum ether, chloroform, ethanol (95\%), methanol; reagents: ammonia, iodine, ferric chloride, acetic, nitric, sulphuric, silicowolframic and $\mathrm{HCl}$, bromocresol green, $\alpha$-naphthol, ninhydrin, gelatin, etc. were purchased from Tianjin Fu-Yu Meticulous Chemical Reagent Company, China.

Test organisms: Organisms such as Staphylococcus aureus (ATCC 25923) and Escherichia coli (ATCC 25922) were used for study. The organisms were maintained by serial sub-culturing every month on nutrient agar slants and incubating at $37{ }^{\circ} \mathrm{C}$ for $18-24 \mathrm{~h}$. The cultures were stored under refrigerated condition. The antifungal activity was tested against Blastomyces albicans (ATCC 10231).

Penicillin (Zhongnuo Pharmaceutical Institute Company, H13021634), gentamycin sulfate injection (Zhenzhou Linrui Pharmaceutical Co. Ltd., H41020318), fluconazole (Tianjin Pharmaceutical Group Xinzheng Co. Ltd, 100108) were served as positive control to determine the sensitivity of Staphylococcus aureus, Escherichia coli, Blastomyces albicans tested, respectively.

Microscopic studies: Microscopic studies were done by transferring the plants to powder (\# 60). Observe powder features of hand sample slides ${ }^{11}$. 
Ash values: Physico-chemical analysis was performed using standard procedures which are helpful in determining the quality and purity of crude drugs, especially in powder form $^{12}$.

Total ash: About $3 \mathrm{~g}$ powder was accurately weighed and taken in a crucible, which was previously ignited and weighed. The powder was spread as a fine, even layer on the bottom of the crucible. The crucible was incinerated gradually by increasing temperature to make it dull red hot until free from carbon. The crucible was cooled and weighed. The procedure was repeated to get constant weight ${ }^{12}$.

Acid insoluble ash: The ash obtained as described above was boiled with $10 \mathrm{~mL}$ of $2 \mathrm{~N} \mathrm{HCl}$ for $10 \mathrm{~min}$. The insoluble ash was collected on an ash less filter paper and washed with hot water. The insoluble ash was transferred into a crucible, ignited and weighed. The procedure was repeated to get a constant weight ${ }^{12}$.

Water soluble ash: The ash obtained as described in the determination of total ash was boiled for 5 min with $25 \mathrm{~mL}$ of water. The insoluble matter was collected on ash less filter paper and washed with hot water. The insoluble ash was transferred into crucible, ignited for $15 \mathrm{~min}$ and weighed. The procedure was repeated to get a constant weight. The weight of insoluble matter was subtracted from the weight of the total ash. The difference of weight was considered as water-soluble $\operatorname{ash}^{12}$. Fluorescence analysis was carried out according to the method of ${ }^{12}$ and Chase and Pratt ${ }^{13}$.

Preliminary physicochemical screening: The powder of dried plants was subjected to continuous soxhlet extraction with various organic solvent such as petroleum ether, benzene, chloroform, methanol and ethanol, respectively. Extractive values of crude drugs are useful for their evaluation, especially when the constituents of a drug can not be readily estimated by any other means. Further, these values indicate the nature of the constituents present in a crude drug ${ }^{14}$.

After concentration and drying of each extract in vacuum desiccator, identification of phytoconstituents was carried out using chemical test.

Determination of poly phenols: Total phenols content in the ethanol extract was determined by the modified FolinCiocalteu method ${ }^{15}$. An aliquot of extract was mixed with 0.5 $\mathrm{mL}$ of Folin-Ciocalteu reagent and $1.5 \mathrm{~mL}$ of sodium carbonate (20\%). The tubes were vortexed for $20 \mathrm{~s}$ and allowed to stand for $10 \mathrm{~min}$ at $75^{\circ} \mathrm{C}$ for colour development. Absorbance was then measured at $760 \mathrm{~nm}$ using UV-VIS spectrophotometer. The amount of total polyphenols in the extract was calculated from the calibration curve in terms of gallic acid equivalents ( $\mathrm{y}=0.09221+137.25 \mathrm{x}, \mathrm{R}=0.999)$.

Test for antibacterial activity: Antibacterial activity of total phenols from $P$. sinjiangensis K.Y. Pan were studied against two bacterial strains viz. Staphylococcus aureus, Escherichia coli. A macrodilution broth susceptibility assay was used, as recommended by NCCLS $(1999)^{16}$ and described in Experiment technique of medical microbiology ${ }^{17}$. The samples were added aseptically to sterile melted Mueller Hinton Broth medium and determined MIC and MBC (minimum inhibitory concentration and maximum bactericidal concentration), standard reference antibiotics (penicillin, gentamycin) were used as positive control. All tests were performed in Mueller Hinton Broth and performed in triplicate.

Test for antifungal activity: The antifungal activity of total phenols from $P$. sinjiangensis K.Y. Pan against fungal isolates (Blastomyces albicans) was evaluated using the broth dilution method. The total phenols were added aseptically to sterile melted Sabouraud's Borth medium and fluconazole was used as a reference antifungal drug. MIC value was determined as the lowest concentration of total phenols was absence of growth was recorded. Each test in this study was repeated triplicate and performed in Sabouraud's Borth.

\section{RESULTS AND DISCUSSION}

The powder microscopy of the plant revealed the presence of fiber, non-glandular hairs, pollen grain, catheter, stomata, glandular scales and hairs, palisade cells. The proximate analysis result shown that the total ash value, acid insoluble ash value, water soluble ash value were $9.54 \pm 0.03,0.83 \pm 0.14$ and $5.59 \pm 0.03 \%$, respectively (Table- 1 ).

TABLE-1

PHYSICO-CHEMICAL ANALYSIS OF $P$. sinjiangensis K.Y. PAN

\begin{tabular}{cc}
\hline Ash values & Percentage* $(\%) \mathrm{w} / \mathrm{w}$ \\
\hline Total ash value & $9.54 \pm 0.03$ \\
Acid insoluble ash & $0.83 \pm 0.14$ \\
Water soluble ash & $5.59 \pm 0.03$ \\
\hline *Average of three determinations \pm SEM. &
\end{tabular}

Successive solvent extractions were shown in percentage of yield. The percentage for ethanol, methanol, petroleum ether, chloroform, benzene and aqueous were 34.35, 24.13, $2.59,1.15,2.03$ and $36.36 \%$, respectively (Table-2).

\begin{tabular}{lc}
\multicolumn{2}{c}{ TABLE-2 } \\
\multicolumn{1}{c}{$\begin{array}{c}\text { SUCCESSIVE SOLVENT EXTRACTIONS } \\
\text { OF } P \text {. sinjiangensis K.Y. PAN }\end{array}$} \\
\hline \multicolumn{1}{c}{ Extractive values } & Percentage* $(\%) \mathrm{w} / \mathrm{w}$ \\
\hline Ethanol solute extractive & 34.35 \\
Methanol solute extractive & 24.13 \\
Petroleum ether solute extractive & 2.59 \\
Chloroform solute extractive & 1.15 \\
Benzene solute extractive & 2.03 \\
Aqueous solute extractive & 36.36 \\
\hline *Average of three determinations.
\end{tabular}

All extracts were than subjected to study chemical nature of the drug (Table-3). Preliminary physicochemical studies revealed that different fraction contains different components.

Fluorescence analysis of the plant powdered and extract were observed under UV (254 and $366 \mathrm{~nm}$ ) and visible right. The results are shown in Table- 4 .

Total phenols content was $9.58 \pm 1.03 \mathrm{mg} \mathrm{QE} / \mathrm{g}$ dry wt. It is well-known that phenolic compounds contribute to quality and nutritional value in terms of modifying colour, taste, aroma and also in providing health beneficial effects.

Tables 5 and 6 showed that the total phenols of $P$. sinjiangensis K.Y. Pan were found to have moderate antimicrobial activity. The results of MIC and MBC values indicated that it has strong inhibition against Blastomyces albicans and considerable activity against Staphylococcus aureus and Escherichia coli, compared with corresponding positive control. 
TABLE-3

PHYTOCHEMICAL TESTS OF THE SUCCESSIVE EXTRACTS OF P. sinjiangensis K.Y. PAN

\begin{tabular}{|c|c|c|c|c|c|c|}
\hline Chemical constituents & $\begin{array}{l}\text { Aqueous } \\
\text { extraction }\end{array}$ & $\begin{array}{c}\text { Petroleum ether } \\
\text { extraction }\end{array}$ & $\begin{array}{c}\text { Ethanol } \\
\text { extraction }\end{array}$ & $\begin{array}{l}\text { Methanol } \\
\text { extraction }\end{array}$ & $\begin{array}{c}\text { Benzene } \\
\text { extraction }\end{array}$ & $\begin{array}{c}\text { Chloroform } \\
\text { extraction }\end{array}$ \\
\hline Tannins & Present & Absent & Present & Present & Absent & Absent \\
\hline Carbohydrates & Present & Absent & Present & Absent & Present & Present \\
\hline Saponins & Absent & Absent & Absent & Absent & Absent & Absent \\
\hline Flavonoids & Absent & Present & Absent & Present & Absent & Absent \\
\hline Alkaloids & Present & Absent & Present & Present & Absent & Absent \\
\hline Triterpenoids & Absent & Present & Absent & Absent & Absent & Absent \\
\hline Proteins and amino acids & Absent & Absent & Absent & Absent & Absent & Absent \\
\hline Fixed oils and fats & Absent & Present & Absent & Present & Absent & Absent \\
\hline Organic acids & Present & Absent & Present & Present & Present & Present \\
\hline
\end{tabular}

TABLE-4

FLUORESCENCE ANALYSIS OF THE SUCCESSIVE EXTRACTS OF $P$. sinjiangensis K.Y. PAN

\begin{tabular}{|c|c|c|c|}
\hline \multirow{2}{*}{ Drug \& reagents } & \multicolumn{2}{|c|}{ UV light } & \multirow{2}{*}{ Visible light } \\
\hline & Short $(254 \mathrm{~nm})$ & Long (366 nm) & \\
\hline Powder as such & Brown & Khaki & Brown \\
\hline Power + Glacial acetic acid & Cream soda & Yellowish brown & Cinnamon \\
\hline Power $+1 \mathrm{~N} \mathrm{H}_{2} \mathrm{SO}_{4}$ & Light brown & Cinnamon & Maroon \\
\hline Power + 1 N Dil. HCl & Dark brown & Brown & Cream soda \\
\hline Poer + conc. $\mathrm{HCl}$ & Dark brown & Brown & Brown \\
\hline Power + Conc. $\mathrm{H}_{2} \mathrm{SO}_{4}$ & Dark purple & Light purple brown & Dark purple \\
\hline Power + $1 \mathrm{~N} \mathrm{NaOH}$ & Cocoa & Khaki & Khaki \\
\hline Power + Methanol & Yellowish-brown & Dark khaki & Khaki \\
\hline Power + Diethyl ether & Khaki & Khaki & Khaki \\
\hline Power + ethanol & Cocoa & Dark cocoa & Cocoa \\
\hline Power + chloroform & Light cocoa & cocoa & Cream soda \\
\hline Power + hexane & Khaki & Light khaki & Brunette \\
\hline Power + ammonia & Dark cocoa & Brown & Light brown \\
\hline Power + toluene & Cocoa & Light khaki & Cocoa \\
\hline Power $+n$-butanol & Dark brown & Light brown & Dark brown \\
\hline
\end{tabular}

\section{ANTIMICROBIAL ACTIVITY OF STANDARD ANTIBIOTICS}

\begin{tabular}{lccc}
\hline \multirow{2}{*}{ Organisms } & Penicillin & Gentamycin & Fluconazole \\
\cline { 2 - 4 } & $\mathrm{MIC}^{\mathrm{a}} / \mathrm{MBC}^{\mathrm{a}}$ & $\mathrm{MIC}^{\mathrm{a}} / \mathrm{MBC}^{\mathrm{a}}$ & $\mathrm{MIC}^{\mathrm{a}} / \mathrm{MBC}^{\mathrm{a}}$ \\
\hline Staphylococcus aureus & 0.03 & 0.06 & \\
Escherichia coli & 0.031 & 0.063 & \\
Blastomyces albicans & 25 & 50 & \\
\hline
\end{tabular}

${ }^{\mathrm{a}}$ Values given as $\mathrm{mg} \mathrm{mL}^{-1}$.

\begin{tabular}{lcc}
\multicolumn{3}{c}{ TABLE-6 } \\
\multicolumn{3}{c}{ ANTIMICROBIAL ACTIVITY OF TOTAL } \\
PHENOLS FROM P. sinjiangensis K.Y. PAN \\
\hline \multirow{2}{*}{ Organisms } & \multicolumn{2}{c}{ Total phenols from P. sinjiangensis K.Y. Pan } \\
\cline { 2 - 3 } \multicolumn{1}{c}{ MIC* } & MBC $^{\text {a }}$ \\
\hline Staphylococcus aureus & 16.254 & 32.508 \\
Escherichia coli & 16.736 & 32.647 \\
Blastomyces albicans & 4.064 & 8.127 \\
\hline${ }^{a}$ Values given as $\mathrm{mg} \mathrm{mL}^{-1}$. & &
\end{tabular}

\section{ACKNOWLEDGEMENTS}

This work was supported by the National Natural Science Foundation of China (Grant No. 81260433).

\section{REFERENCES}

1. C. Liu, J. Wang and J. Yang, J. Chin. Med. Mater., 23, 557 (2000).

2. L. Fulong, L. Wen, Y. Xiaojie, F. Guilan and H. Shilin, Chin. J. Hemorheol., 11, 175 (2001).

3. Z. Yongyan and Z. Wenxia, Shanxi J. Tradit. Chin. Med., 24, 655 (2003).

4. H. Meixue, J. Chin. Med., 19, 13 (1998).

5. X. Hongmei, L. Qingyun, D. Min, D. Peng and Z. Xiaomei, J. Anhui Tradit. Chin. Med. Coll., 19, 46 (2000).

6. Z. Jianhua and W. Anlian, Anhui J. Prev. Med., 4, 49 (1998).

7. W. Zhenyu, Outline of New China Herbals, Shanghai Science and Technology Press, Shanghai, p. 210 (1990).

8. S.G. Tian, X.Y. Zhou and H.Y. Gong, Phcog. Mag., 7, 4 (2011).

9. Y. Yuanyuan, M. Xiaokang, G. Zhengyi, Z. Gang and W. Yuqing, Her. Med., 27, 763 (2008).

10. S.J. Xu, L. Yang, Q. L. Lin, Z.J. Liu, Q.R. Feng, L. Ma and M. Liu, Chromatographia, 68, 5 (2008)

11. State Pharmacopeia Committee of China, Pharmacopoeia of People's Republic of China, 11th Appendix II C: pp.18-20 (2010).

12. State Pharmacopeia Committee of China, Pharmacopoeia of People's Republic of China, 11th Appendix IX K: p. 53 (2010).

13. C.R. Chase and R.J. Pratt, J. Am. Pharmacol. Assoc., 38, 32 (1949).

14. K.R. Khandelwal, Practical Pharmacognosy, Nirali Prakashan, Pune, India, edn. 9, pp. 157-158 (2002).

15. K. Wolfe, X. Wu and R.H. Liu, J. Agric. Food Chem., 51, 609 (2003).

16. NCCLS (National Committee for Clinical Laboratory Standards), Performance Standards for Antibacterial Susceptibility Testing (9th International Supplement), M 100-S9 (1999).

17. Z.Y. Guan, A.L. Wang and J. Li, Experiment Technique of Medical Microbiology, Chemical Industry House, China, pp. 115-117 (2006). 